\title{
Biomarcadores de Suscetibilidade à Endometriose
}

\author{
Biomarkers of Susceptibility to Endometriosis
}

Liliane Cristina Nakata ${ }^{1}$, Eny Maria Goloni-Bertollo ${ }^{1}$, Izaura dos Santos ${ }^{2}$, Antonio Hélio Oliani ${ }^{2}$, Denise Cristina Mós Vaz $^{2}$, Gustavo Henrique de Oliveira ${ }^{2}$, Érika Cristina Pavarino-Bertelli ${ }^{1}$

\section{RESUMO}

Objetivos: verificar as freqüências dos genótipos nulos para os genes GSTT1 e GSTM1, assim como as freqüências do alelo polimórfico do gene CYP1A1 em um grupo de mulheres com endometriose, e comparar essas freqüências com aquelas observadas em um grupo que não apresenta a doença (controle), visando uma possivel identificação de biomarcadores de suscetibilidade à endometriose.

Métodos: foram incluídas 50 mulheres com sinais clínicos sugestivos de endometriose e que foram submetidas à videolaparoscopia e biópsia das lesões avaliadas histologicamente. A endometriose foi confirmada em 25 mulheres, consideradas como o grupo caso, e resultado negativo foi observado nas outras 25 (grupo controle). Os genótipos nulos para os genes GSTT1 e GSTM1 foram avaliados pela reação em cadeia da polimerase (PCR) multiplex. A investigação do alelo polimórfico do gene CYP1A1 foi realizada por meio da técnica de PCRRFLP (polimorfismos de comprimento de fragmentos de restrição). Para a análise estatística utilizou-se o teste exato de Fisher.

Resultados: em ambos os grupos, as freqüências dos polimorfismos de deleção apresentaram valore s de $16 \%$ para o gene GSTT1 e de 44\% para o gene GSTM1. Portanto, os resultados não mostraram diferenças na distribuição dos genótipos nulos GSTT1 e GSTM1 entre os grupos estudados. A diferença da freqüência alélica para o alelo $m 1$ do gene CYP1A1, embora não significante, foi mais elevada nas mulheres com endometriose $(0,22)$ quando comparada àquelas do grupo controle $(0,14)$.

Conclusão: os resultados não mostraram uma associação entre os polimorfismos avaliados $e$ o diagnóstico de endometriose.

PALAVRAS-CHAVE: Endometriose. Glutahtione S transferase. Biometabolismo. Polimorfismo. PCR.

\section{Introdução}

A endometriose é doença poligênica/ multifatorial, caracterizada pelo crescimento de tecido endometrial fora da cavidade uterina e, que freqüentemente resulta em vários problemas ginecológicos incluindo dispareunia, dismenorréia, dor pélvica e infertilidade ${ }^{1}$. Embora aproximada-

\footnotetext{
${ }^{1}$ Departamento de Biologia Molecular e ${ }^{2}$ Departamento de Ginecologia e Obstetrícia da Faculdade de Medicina de São José do Rio Preto (FAMERP) SP

Correspondência: Liliane Cristina Nakata

Departamento de Biologia Molecular

Faculdade de Medicina de São José do Rio Preto - FAMERP Av. Brigadeiro Faria Lima 5416

15090-000 - São José do Rio Preto - SP

Telefone: (17) 210-5700, ramal 5811

e-mail: erika@famerp.br
}

mente $15 \%$ das mulheres em idade reprodutiva desenvolvam a doença ${ }^{2}$, sua etiologia ainda permanece obscura. A teoria da menstruação retrógrada tem sido amplamente utilizada para explicar sua origem. Ela propõe que células endometriais viáveis, descamadas durante a menstruação, atingiriam por refluxo, por meio das tubas uterinas, a cavidade peritoneal com conseqüente implantação e crescimento local, uma vez que os macrófagos peritoneais de pacientes com endometriose não apresentam capacidade de digerir eficientemente o refluxo menstrual ${ }^{3,4}$.

O estresse oxidativo tem sido apontado como fator potencial envolvido na fisiopatologia da endometriose. A produção de espécies reativas de oxigênio pelo fluido peritoneal parece estar aumentada em mulheres com a doença e a expressão 
alterada de enzimas envolvidas na defesa contra o estresse oxidativo também já foi observada no endométrio de mulheres com esta condição. A produção excessiva de espécies reativas de oxigênio pode também ser resultado da exposição a compostos ambientais que rompem o balanço entre pró-oxidantes e antioxidantes ${ }^{5}$.

É possível que polimorfismos genéticos em enzimas envolvidas na produção e eliminação de espécies reativas de oxigênio, bem como naquelas que participam da ativação e detoxificação de compostos exógenos (xenobióticos), modulem os niveis de biomarcadores de dano oxidativo ${ }^{6}$.

A maquinaria de metabolização xenobiótica possui dois tipos de enzimas: as de metabolismo oxidativo mediado, ou de fase I, e as enzimas conjugadas, ou de fase II. Muitos compostos são convertidos a metabólitos altamente reativos pelas enzimas oxidativas de fase I, principalmente enzimas da superfamília do citocromo P450 (CYPs). Em contraposição, as reações da fase II envolvem a conjugação com um substrato endógeno, por meio das glutationa S-transferases (GSTs), UDPglucoroniltransferases e $\mathrm{N}$-acetiltransferases (NATs), que agem como enzimas inativadoras dos produtos da fase I, tornando os metabólitos hidrofílicos e passíveis de excreção ${ }^{7}$.

Dentre as enzimas GSTs mais conhecidas estão as GSTT1 e GSTM1. O gene GSTM1 é polimórfico na população humana, com dois alelos funcionais ativos que apresentam a mesma eficiência metabólica e um alelo com atividade nula ${ }^{7}$. Este último não sintetiza seu produto protéico devido a grande deleção no gene. Homozigotos para o alelo GSTM1 nulo são considerados grupo de risco, principalmente se expostos a elevados níveis de carcinógenos e compostos químicos, devido ao defeito enzimático em seu sistema de detoxificação ${ }^{8}$. Assim como o gene GSTM1, o GSTT1 também é polimórfico na população humana, podendo apresentar fenótipo nulo por deleção ${ }^{7}$. Em relação às enzimas CYPs, uma das mais extensivamente estudadas é a CYP1A1. Um polimorfismo de restrição $M s p I$ (CYP1A $1 \mathrm{~m} 1)$ na região $3^{\prime}$ não codificante do gene, resultante da transição de uma timina para citosina $(\mathrm{T} \rightarrow \mathrm{C})$, parece promover aumento da sua expressão ${ }^{9}$.

Desse modo, diferenças genéticas na regulação, expressão e atividade dos genes de fases I e II podem ser o fator crucial na suscetibilidade a certos tipos de doenças ${ }^{7}$. Realmente, polimorfismos em genes do biometabolismo têm sido identificados em inúmeras populações ${ }^{7}$ e relacionados com neoplasias de pulmão ${ }^{10}$, fibrose cística $^{11}$, bronquite crônica ${ }^{8}$ e endometriose ${ }^{9,12,13}$.
Neste contexto, este estudo teve como objetivo determinar as freqüências dos genótipos nulos para os genes GSTT1 e GSTM1, assim como as freqüências do alelo polimórfico CYP1A1m l em um grupo de mulheres com endometriose, e comparar essas freqüências com aquelas observadas em grupo que não apresenta a doença, visando uma possível identificação de biomarcadores de suscetibilidade à endometriose.

\section{Pacientes e Métodos}

Trata-se de estudo caso-controle. Foram selecionadas 50 mulheres submetidas videolaparoscopia no Serviço de Ginecologia e Obstetrícia do Hospital de Base de São José do Rio Preto. As indicações da videolaparoscopia foram: infertilidade (24 casos), algia pélvica (16 casos), dismenorréia secundária (6 casos) e em quatro casos foram referidas ambas as queixas, dismenorréia e infertilidade. Dentre as mulheres avaliadas, 25 pacientes tiveram diagnóstico de endometriose, confirmada pelo exame histopatológico, e 25 não apresentaram a doença (grupo controle). A faixa etária variou de 21 a 47 anos $(34,9 \pm 6,1)$. A classificação da etnia foi baseada na análise de três gerações antecedentes ${ }^{14}$, e mostrou 42 caucasóides e oito negróides. As pacientes incluídas no estudo eram provenientes da região de São José do Rio Preto, noroeste do Estado de São Paulo, e participaram do estudo após a assinatura do termo de consentimento livre e esclarecido. O estudo foi aprovado pelo Comitê de Ética em Pesquisa da Faculdade de Medicina de São José do Rio Preto (CEP-FAMERP) e pelo Conselho Nacional de Ética em Pesquisa (CONEP).

O DNA genômico foi extraído a partir de 9 $\mathrm{mL}$ de sangue periférico segundo a técnica de Abdel-Rahman et al. ${ }^{15}$. A amostra de sangue periférico foi colhida em tubo contendo anticoagulante (EDTA) e os linfócitos foram isolados com auxílio de Ficoll-Paque Plus (Amersham Biosciences). O DNA genômico foi obtido adicionando aos linfócitos isolados SDS (sodium dodecyl sulfate), proteinase $\mathrm{K}$ e RNAse A. Após purificação com $\mathrm{NaCl}$, o DNA foi precipitado com etanol e armazenado a $-20^{\circ} \mathrm{C}$ em tampão Tris-EDTA para posterior análise.

A análise para os genes GSTT1 e GSTM1 foi realizada simultaneamente pela reação em cadeia da polimerase (PCR) multiplex, segundo AbdelRahman et al. ${ }^{16}$. A amplificação da seqüência do DNA de interesse foi obtida por 35 ciclos que compreenderam etapas de desnaturação do DNA a $94^{\circ} \mathrm{C}$ 
por 2 minutos, anelamento das seqüências iniciadoras da reação (primers) a $59^{\circ} \mathrm{C}$ por 1 minuto e extensão das cadeias de DNA pela adição dos nucleotídeos a $72^{\circ} \mathrm{C}$ por 1 minuto. Uma seqüência do exon 7 do gene CYP1A1 foi coamplificada como controle interno. Os produtos de PCR foram analisados em gel de agarose $1,5 \%$ corado com brometo de etídio, sendo que o genótipo nulo (presença de ambos alelos com deleção) para os genes GSTT1 e GSTM1 foi identificado pela ausência dos fragmentos de amplificação de 480 pares de base (pb) e 219 $\mathrm{pb}$, respectivamente. A presença do fragmento de $312 \mathrm{pb}$ corresponde à seqüência amplificada do gene CYP1A1 e revela o sucesso da reação de amplificação.

A técnica de PCR-RFLP, que compreende a amplificação da seqüência polimórfica do DNA seguida de digestão por enzima de restrição, foi realizada para investigar o alelo polimórfico $(\mathrm{m} 1)$ do gene CYP1A1, utilizando primers e condições segundo Arvanitis et al. ${ }^{9}$. Assim, a amplificação foi obtida por 35 ciclos que compreenderam etapas de desnaturação do DNA a $94^{\circ} \mathrm{C}$ por 30 segundos, de anelamento dos primers a $58^{\circ} \mathrm{C}$ por 30 segundos e de extensão das cadeias à $72^{\circ} \mathrm{C}$ por 30 segundos. Os produtos de PCR foram digeridos com a enzima de restrição $M s p I$ e os fragmentos visualizados em gel poliacrilamida $9,6 \%$ corado com nitrato de prata. Um fragmento de $340 \mathrm{pb}$ derivado do alelo selvagem (wt) não é digerido pela enzima e um fragmento do mesmo tamanho do alelo polimórfico (m1) é digerido em fragmentos de 206 e 134 pb. Os individuos heterozigotos apresentam os três fragmentos (340, 206 e $134 \mathrm{pb})$.

Para a análise estatística das freqüências dos genótipos obtidos utilizou-se o teste exato de Fisher, com nível de significância de 5\%.

\section{Resultados}

Os resultados da distribuição genotípica para cada polimorfismo nas pacientes com endometriose e no grupo controle encontram-se na Tabela 1. A prevalência dos genótipos nulos [-] GSTT1 e GSTM1 foi de 16 e de 44\%, respectivamente, tanto nas pacientes com endometriose como no grupo controle e, portanto, não houve diferenças significantes ( $p=1,29$ e $p=1,22$; respectivamente). Para o alelo polimorfico CYP1A1m1, a freqüência alélica foi mais elevada nas mulheres com endometriose $(0,22)$ quando comparada ao grupo controle $(0,14)$, mas a diferença não foi significante. Duas pacientes com a doença foram homozigotas para o alelo $\mathrm{m} 1$ (genótipo $\mathrm{m} 1 / \mathrm{m} 1$ ).
Tabela 1 - Distribuição dos genótipos individuais nas mulheres com endometriose e no grupo controle.

\begin{tabular}{lcrrr}
\hline Genótipo & \multicolumn{2}{c}{ Endometriose } & \multicolumn{2}{c}{ Controle } \\
& $\mathbf{n}$ & $\%$ & $\mathbf{n}$ & $\%$ \\
\hline GSTT1 & & & & \\
Positivo [+] & 21 & 84 & 21 & 84 \\
$\quad$ Nulo [-] & 4 & 16 & 4 & 16 \\
GSTM1 & & & & \\
Positivo [+] & 14 & 56 & 14 & 56 \\
Nulo [-] & 11 & 44 & 11 & 44 \\
CYP1A1 & & & & \\
wt/wt & 16 & 64 & 18 & 72 \\
wt/m1 & 7 & 28 & 7 & 28 \\
m1/m1 & 2 & 08 & 0 & - \\
\hline
\end{tabular}

A Tabela 2 mostra a distribuição dos genótipos combinados dos genes CYP1A1, GSTT1 e GSTM1 nas pacientes com endometriose e no grupo controle. O genótipo nulo [-] combinado para os genes GSTT1 e GSTM1 foi observado em 12\% das mulheres de ambos os grupos (endometriose e controle). As maiores freqüências de combinações genotípicas nos dois grupos considerando pelo menos a presença de um genótipo desfavorável, ou seja, a presença de um polimorfismo (alelo $\mathrm{m} 1$ e GSTs nulos [-]), foram as combinações CYP1A1 wt/wt, GSTT1[+] e GSTM1[-] (20\%) e CYP1A1 wt/ m1, GSTT1 [+] e GSTM1 [+] (16\%).

Tabela 2 - Freqüências de genótipos combinados nas mulheres com endometriose e no grupo controle.

\begin{tabular}{ccc}
\hline $\begin{array}{c}\text { Genótipos } \\
\text { (CYP1A1, GSTT1, GSTM1) }\end{array}$ & $\begin{array}{c}\text { Endometriose } \\
\mathbf{n}(\%)\end{array}$ & $\begin{array}{c}\text { Controle } \\
\mathbf{n}(\%)\end{array}$ \\
\hline $\mathrm{wt} / \mathrm{wt},[+],[+]$ & $8(32)$ & $9(36)$ \\
$\mathrm{wt} / \mathrm{m} 1,[+],[+]$ & $4(16)$ & $4(16)$ \\
$\mathrm{m} 1 / \mathrm{m} 1,[+],[+]$ & $1(4)$ & $0(-)$ \\
$\mathrm{wt} / \mathrm{wt},[-],[+]$ & $0(-)$ & $1(4)$ \\
$\mathrm{wt} / \mathrm{m} 1,[-],[+]$ & $1(04)$ & $0(0)$ \\
$\mathrm{m} 1 / \mathrm{m} 1,[-],[+]$ & $0(0)$ & $0(0)$ \\
$\mathrm{wt} / \mathrm{wt},[+],[-]$ & $5(20)$ & $5(20)$ \\
$\mathrm{wt} / \mathrm{m} 1,[+],[-]$ & $2(8)$ & $3(12)$ \\
$\mathrm{m} 1 / \mathrm{m} 1,[+],[-]$ & $1(4)$ & $0(-)$ \\
$\mathrm{wt} / \mathrm{wt},[-],[-]$ & $3(12)$ & $3(12)$ \\
$\mathrm{wt} / \mathrm{m} 1,[-],[-]$ & $0(-)$ & $0(-)$ \\
$\mathrm{m} 1 / \mathrm{m} 1,[-],[-]$ & $0(0)$ & $0(-)$ \\
\hline
\end{tabular}

A genotipagem para os genes GSTT1, GSTM1 e CYP1A1 é apresentada nas Figuras 1 e 2. 


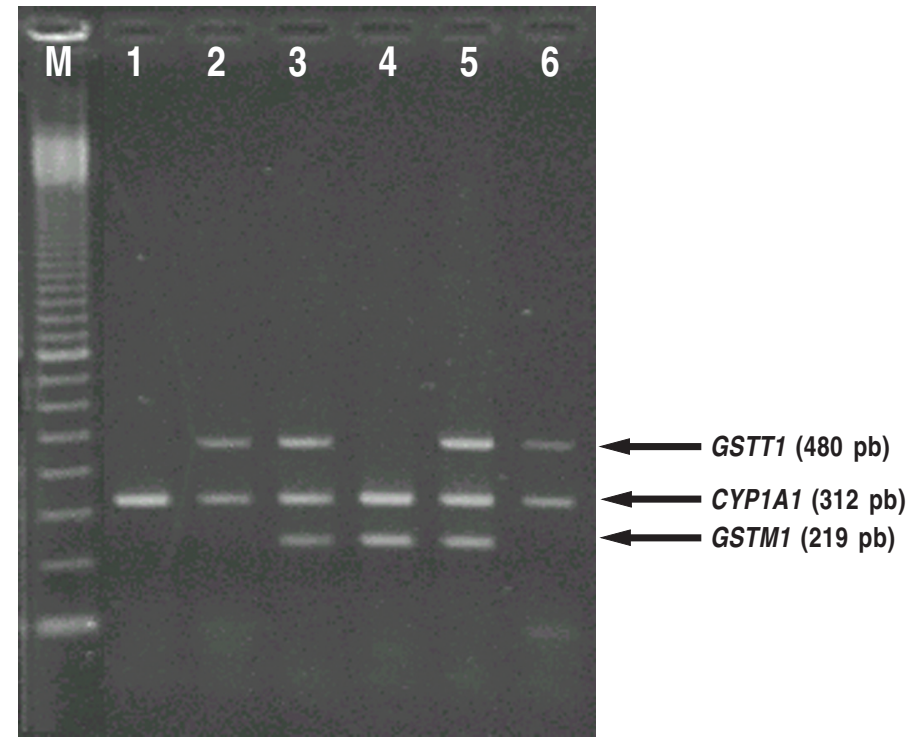

Figura 1 - Fotografia de gel de agarose 1,5\% corado com brometo de etídio para visualização, sob luz ultravioleta, da eletroforese de seis amostras de pacientes com endometriose submetidas à amplificação dos segmentos polimórficos de deleção dos genes GSTT1 e GSTM1. O genótipo nulo para os genes GSTT1 e GSTM1 foi identificado pela ausência dos fragmentos de amplificação de 480 pares de base (pb) e 219 pb, respectivamente. 0 fragmento de 312 pb é o controle interno de amplificação que corresponde a uma seqüência do gene CYP1A1. Os genótipos GSTT1/GSTM1 foram classificados em nulo [-] e não nulo [+]: coluna $1(-/-)$, colunas 2 e $6(+/-)$, colunas 3 e 5 $(+/+)$, coluna $4(-/+)$. O marcador de peso molecular de $100 \mathrm{pb}$ corresponde à coluna $\mathrm{M}$.

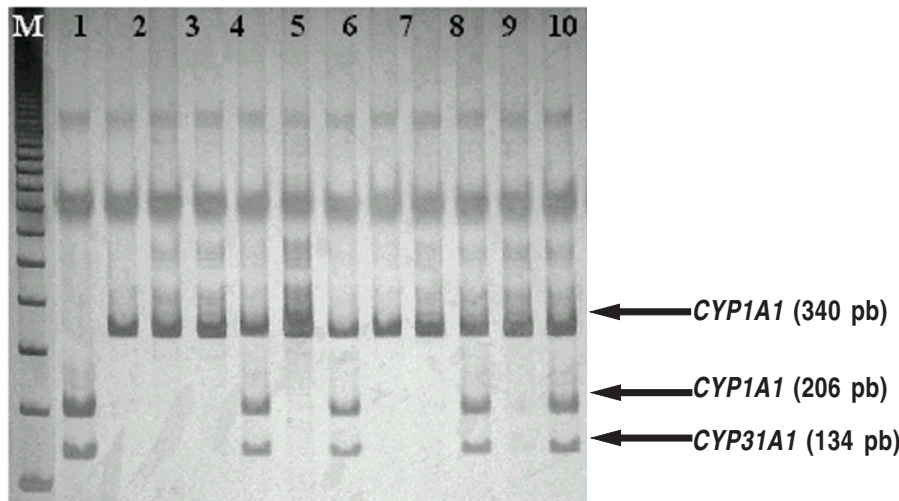

Figura 2 - Fotografia de gel de poliacrilamida 9,6\% corado com nitrato de prata para visualização da eletroforese de 12 amostras de pacientes com endometriose submetidas à amplificação do segmento polimórfico do gene CYP1A1 seguida da digestão com a enzima Mspl que discrimina os alelos selvagem (wt) e polimórfico (m1). O fragmento de 340 pares de base $(\mathrm{pb})$ é derivado da digestão quando o indivíduo apresenta 0 alelo wt, e os fragmentos de 206 e $134 \mathrm{pb}$, quando o indivíduo apresenta o alelo m1. 0 genótipo para o gene CYP1A1 foi classificado em homozigoto selvagem (wt/wt), colunas $2,3,4,6,8,9$ e 11; homozigoto polimórfico ( $\mathrm{m} 1 / \mathrm{m} 1)$, coluna 1 e heterozigoto $(\mathrm{wt} / \mathrm{m} 1)$, colunas $5,7,10$ e 12. 0 marcador de peso molecular de $100 \mathrm{pb}$ corresponde à coluna $\mathrm{M}$.

\section{Discussão}

A disponibilidade de informações sobre os polimorfismos CYP1A1m1, GSTM1 e GSTT1 na população brasileira é escassa. Recentemente, Rossit et al. ${ }^{17}$, em estudo realizado em brasileiras provenientes dos Estados do Pará e São Paulo, mostraram freqüência de 47,3 e $18 \%$ para os genótipos nulos dos genes GSTM1 e GSTT1, respectivamente. Em nosso estudo, freqüências similares foram observadas para estes genótipos (44\% para GSTM1 e 16\% para GSTT1). Baranova et al. ${ }^{12}$ relataram alta freqüência do genótipo nulo GSTM1 em mulheres francesas com endometriose em relação ao controle $(76,9$ vs $45,8 \%)$ e concluíram que este genótipo representa fator de predisposição para endometriose. Outros autores também têm correlacionado o genótipo nulo GSTM1 com o desenvolvimento da endometriose e menos freqüentemente com o GSTT1 $1^{9,12,13}$. Nossos resultados, embora preliminares, não mostraram esta associação, e estão de acordo com o trabalho de Baxter et al. ${ }^{18}$, que avaliaram 84 pacientes com endometriose e não identificaram freqüências elevadas para o gene GSTM1. Estes autores sugerem a necessidade de estudos adicionais para confirmar a contribuição deste polimorfismo para o desenvolvimento da endometriose. Além disto, observaram que o genótipo nulo para GSTM1 foi significativamente elevado no grupo das pacientes com câncer ovariano em relação ao controle $(59,0$ vs $48,9 \%)$ e sugeriram que focos endometrióticos em mulheres com este genótipo podem apresentar transformação maligna devido à ineficiência no controle do estresse oxidativo. Já é conhecido o fato de que o gene GSTM1 pode desempenhar papel crítico na detoxificação de produtos do estresse oxidativo produzidos durante o reparo do epitélio ovariano ${ }^{19}$.

Uma vez que a expressão do gene CYP1A1 parece ser regulada na transcrição por fatores resultantes do estresse oxidativo ${ }^{20}$; sua elevada atividade pode também ser deletéria e contribuir para a suscetibilidade a algumas, doenças; incluindose a endometriose. Já foi demonstrado que o genótipo combinado CYP1A1 wt/ml ou $\mathrm{ml} / \mathrm{ml}$ e GSTM1 nulo aumentam este risco ${ }^{13}$. Em nosso estudo, embora o alelo $\mathrm{m} 1$ tenha sido mais freqüente nas pacientes com endometriose e duas delas apresentassem o genótipo homozigoto $\mathrm{m} 1 /$ $\mathrm{m} 1$, a combinação $C Y P 1 A 1 \mathrm{wt} / \mathrm{m} 1$ ou $\mathrm{m} 1 / \mathrm{ml}$ e GSTM1 nulo, estas diferenças não foram significantes quando comparadas com o grupo controle, provavelmente devido ao pequeno número de indivíduos analisados neste estudo preliminar.

Outros genes candidatos à associação com risco para endometriose que também merecem investigação incluem o gene GALT (galactose-1fosfato uridil transferase), cuja alteração no exon 10, resultando em erros no metabolismo da galactose, foi associada ao risco aumentado de menstruação retrógrada ${ }^{21}$, e o gene para produção de aromatase, que é essencial para a biossintese 
do estrógeno ${ }^{22}$. Também merecem atenção genes envolvidos nos processos de imuno-regulação, como IL-10 (interleucina 10), e que codificam receptores hormonais de andrógeno, de estrógeno e de progesterona ${ }^{2,23-25}$.

\section{ABSTRACT}

Objective: to determine GSTT1 and GSTM1 null genotype frequencies as well as CYP1A1 polymorphic allele frequencies in a group of women with endometriosis, and to compare these frequencies with those observed in a group without endometriosis (control), aiming at a possible identification of biomarkers of susceptibility to endometriosis.

Methods: a total of 50 women with suggestive clinical signs of endometriosis underwent videolaparoscopy and biopsies were evaluated histologically. Endometriosis was present in 25 women (case group). Negative results were found in 25 women (control group). GSTT1 and GSTM1 null genotypes were assessed by multiplex polymerase chain reaction $(P C R)$. The investigation of the polymorphic allele of the gene CYP1A1 was performed by PCR-RFLP (restriction fragment length polymorphism). For statistical analysis, the Fisher exact test was used.

Results: in both groups, the deletion polymorphism frequencies presented values of 16\% for the gene GSTT1 and of 44\% for the gene GSTM1; therefore, the results did not show differences in the distribution of the GSTT1 and GSTM1 null genotypes among the studied groups. The allelic frequency for the $m 1$ allele of the gene CYP1A1 was higher in the women with endometriosis (0.22), although not statistically significant, when compared to the control group (0.14).

Conclusion: the results did not show an association between the evaluated polymorphisms and the endometriosis diagnosis.

KEYWORDS: Endometriosis. Glutathione S transferase. Biometabolism. Polymorphism. PCR.

\section{Referências}

1. Bischoff FZ, Simpson JL. Heritability and molecular genetic studies of endometriosis. Hum Reprod Update 2000; 6:37-44.

2. Wieser F, Schneeberger C, Tong D, Tempfer C, Huber JC, Wenzl R. PROGINS receptor gene polymorphism is associated with endometriosis. Fertil Steril 2002; 77:309-12.

3. Seli E, Berkkanoglu M, Arici A. Pathogenesis of endometriosis. Obstet Gynecol Clin North Am 2003; 30:41-61.
4. Santanam N, Murphy AA, Parthasarathy S. Macrophages, oxidation, and endometriosis. Ann N Y Acad Sci 2002; 955:183-98.

5. Van Langendonckt AV, Casanas-Roux F, Donnez J. Oxidative stress and peritoneal endometriosis. Fertil Steril 2002; 77:861-70.

6. Hong $\mathrm{YC}$, Lee $\mathrm{KH}$, Yi $\mathrm{CH}$, Ha EH, Christiani DC. Genetic susceptibility of term pregnant women to oxidative damage. Toxicol Lett 2002; 129:255-62.

7. Rossit A, Conforti-Froes NDT. Suscetibilidade genética, biometabolismo e câncer. Rev Soc Bras Cancerol 2000; 3:26-30.

8. Baranova H, Perriot J, Albuisson E, et al. Peculiarities of the GSTM1 0/0 genotype in French heavy smokers with various type of chronic bronchits. Hum Genet 1997; 99:822-6.

9. Arvanitis DA, Goumenou AG, Matalliotakis IM, Koumantakis EE, Spandidos DA. Low penetrance genes are associated with increased susceptibility to endometriosis. Fertil Steril 2001; 76:1202-6.

10.Hung RJ, Boffetta P, Brockmoller J, et al. CYP1A1 and GSTM1 genetic polymorphisms and lung cancer risk in Caucasian non-smokers: a pooled analysis. Carcinogenesis 2003; 24:875-82.

11.Baranov VS, Ivaschenko T, Bakay B, et al. Proportion of the GSTM1 0/0 genotype in some Slavic populations and its correlation with cystic fibrosis and some multifactorial diseases. Hum Genet 1996; 97:516-20.

12.Baranova $\mathrm{H}$, Canis $\mathrm{H}$, Ivaschenko $\mathrm{T}$, et al. Possible involvement of arylamine $\mathrm{N}$-acetyltransferase 2 , glutathione S-transferases M1 and T1 genes in the development of endometriosis. Mol Hum Reprod 1999; 5:636-41.

13.Arvanits DA, Koumantakis GE, Goumenou AG, Matalliotakis IM, Koumantakis EE, Spandidos DA. CYP1A1, CYP19 and GSTM1 polymorphisms increase the risk of endometriosis. Fertil Steril 2003; 79 (Suppl 1):702-9.

14.Arruda VR, Siqueira LH, Gonçalves MS, et al. Prevalence of the mutation C677T in the methylene tetrahydrofolate redutase gene among distinct ethnic groups in Brazil. Am J Med Genet 1998; 78:332-5

15.Abdel-Rahman SZ, Nouraldeen AM, Ahmed AE. Molecular interaction of [2,3-14c]-acrylonitrile with DNA in gastric tissues of rat. J Biochem Toxicol 1994; 9:191-8.

16.Abdel-Rahman SZ, el-Zein RA, Anwar WA, Au WW. A multiplex PCR procedure for polymorphic analysis of GSTM1 and GSTT1 genes in population studies. Cancer Lett 1996; 107:229-33.

17. Rossit ARB, Cabral IR, Conforti-Froes NDT. Avaliação das freqüências alélicas de genes do biometabolismo em uma população brasileira. Genet Mol Biol 1999; 22:23. 
18. Baxter SW, Thomas EJ, Campbell IG. GSTM1 null polymorphism and susceptibility to endometriosis and ovarian cancer. Carcinogenesis 2001; 22:63-5.

19.Sarhanis P, Redman C, Perrett C, et al. Epithelial ovarian cancer: influence of polymorphism at the glutathione S-transferase GSTM1 and GSTT1 loci on p53 expression. Br J Cancer 1996; 74:1754-61.

20.Barouki R, Morel Y. Repression of cytochrome P450 1A1 gene expression by oxidative stress: mechanisms and biological implications. Biochem Pharmacol 2001; 61:511-6.

21.Stefansson H, Einarsdottir A, Geirsson RT, et al. Endometriosis is not associated with or linked to the GALT gene. Fertil Steril 2001; 76:1019-22.
22.Bulun SE, Zeitoun KM, Takayama K, Sasano H. Estrogen biosynthesis in endometriosis: molecular basis and clinical relevance. J Mol Endocrinol 2000; 25:35-42.

23.Kitawaki J, Obayashi H, Ohta M, et al. Genetic contribution of the interleukin-10 promoter polymorphism in endometriosis susceptibility. Am J Reprod Imunol 2002; 47:12-8.

24.Hsieh YY, Chang CC, Tsai FJ, Wu JY, Tsai CH, Tsai HD. Androgen receptor trinucleotide polymorphism in endometriosis. Fertil Steril 2001; 76:412-3.

25.Georgiou I, Syrrou M, Bouba I, et al. Association of estrogen receptor gene polymorphism with endometriosis. Fertil Steril 1999; 72:164-6.

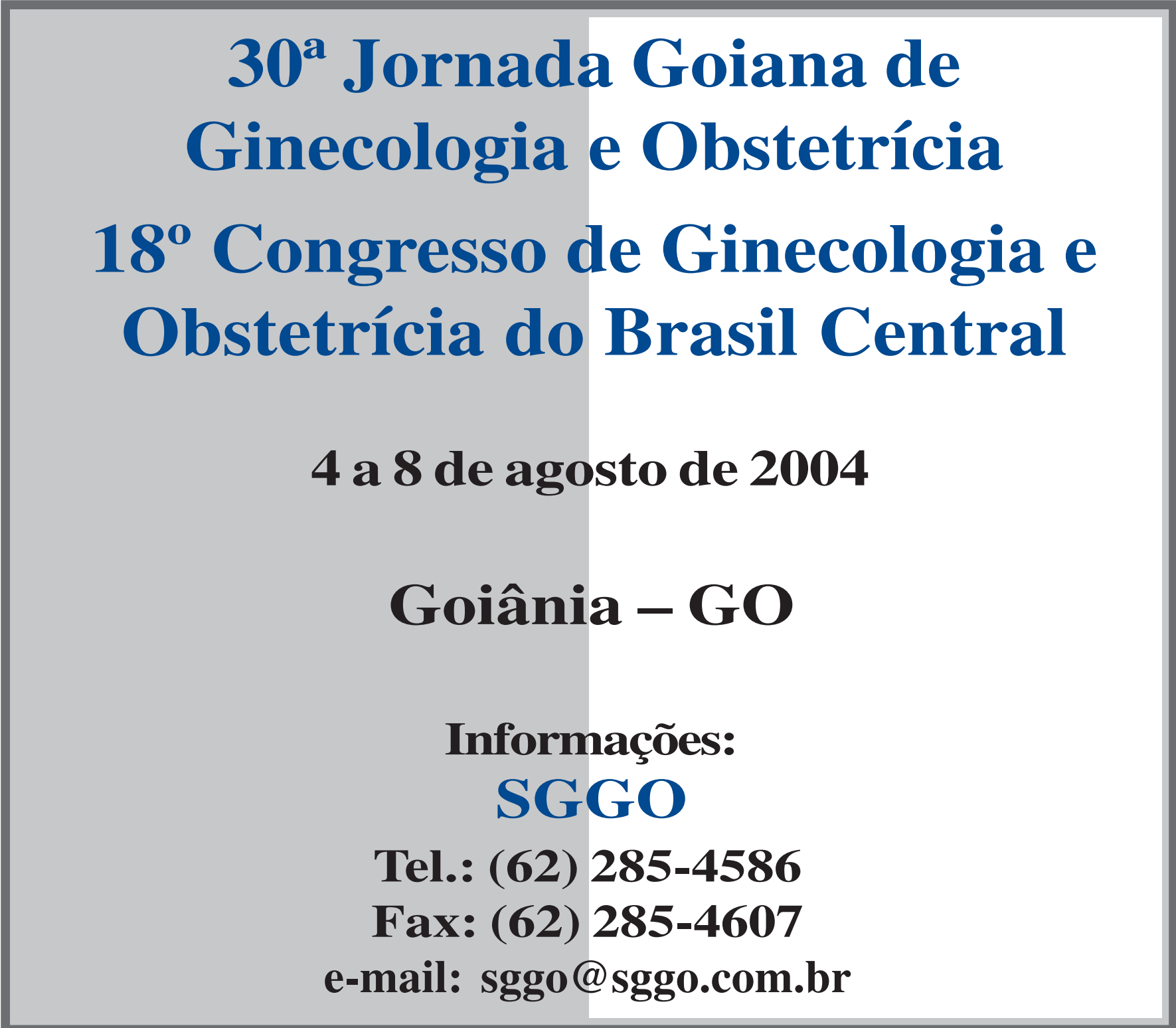

